\title{
Adaptability Evaluation of Polymer Flooding for Zahra Oil Field
}

\author{
Peng Lv*, Mingyuan Li, Meiqin Lin, Bo Peng, Zhaoxia Dong and Zihao Yang
}

Enhanced Oil Recovery Research Institute, China University of Petroleum (Beijing), Beijing, 102249

\begin{abstract}
Viscosity-concentration and temperature performance are the prerequisite constraint factor of the application of polymer flooding in the oilfield. The static and dynamic adsorption of the polymer in the core can affect the performance of polymer flooding. Based on the viscosity-concentration, temperature and the static, dynamic adsorption results of six kinds of polymers, DQ3500 is chosen as the most suitable polymer for Zahra oilfield. Its affects show that oil recovery is increased by $7 \%$ and water cut is reduced by $20 \%$.
\end{abstract}

Keyword: Enhanced oil recovery, Polymer viscosity-concentration, Static dynamic adsorption, Temperature performance, Water cut.

\section{INTRODUCTION}

Viscosity-concentration, temperature performance are the prerequisite constraint for polymer flooding in an oilfield [1] .Static adsorption and dynamic adsorption of the polymer not only can restrict the dissemination properties of polymers directly [2-5], but also can affect the economic effects of polymer flooding in a specific reservoir. In this paper, adaptability of polymer flooding of 6 kinds of polymers in Zahra oil field is researched. Based on the viscosityconcentration, temperature relationship and the static, dynamic adsorption results of the 6 kinds of polymers, the polymer DQ3500 is selected as the most suitable polymer for polymer flooding in Zahra oil field. Its effects on enhancing oil recovery are analyzed.

\section{EXPERIMENTAL APPARATUS AND MATERIALS}

\subsection{Experimental Apparatus}

The apparatus include DMA 45 densitometer, Ultraviolet spectrophotometer, MCR301 viscometer, displacement equipment(pressure gage, thermostat, core gripper), $\mathrm{PH}$ meter, etc. and $\mathrm{MgCl}_{2} \cdot 6 \mathrm{H}_{2} \mathrm{O}(>99 \%)$ are provided by Beijing Modern East Fine Chemical Co.. Zahra dewatered oil $\left(\mathrm{T}=72^{\circ} \mathrm{C}\right.$, $\left.\eta=7.46 \mathrm{mPas}, \rho=0.8290 \mathrm{~g} / \mathrm{cm}^{3}\right)$ Polymer MO4000, FP3640s, FP6040s, DQ3500, KYPAM-2 and KYPAM-5.

\section{EVALUATION OF POLYMER FLOODING IN ZAHRA FIELD}

\subsection{Formation Brine in Zahra field}

The composition of formation brine in Zahra field is shown as in Table 1. In the artificial simulation, the water based on the composition of the formation brine in Zahra field is prepared and used for preparing chemical solution in this research.

There are 6 polymers have been selected in the evaluation of polymer flooding for Zahra crude oil. The parameters of $M_{\mathrm{w}}$, hydrolyzing degree, filtration factor, water insoluble matters, dissolving time and solid content of the 6 polymers are selected and listed in Table 2 . From Table 2, it can be found that the content of all four polymers is higher than $86.5 \%$. The dissolving time of all four polymers is less than 2 hours. The results show that all of the polymers

Table.1. Ion composition of formation brine in Zahra field.

\begin{tabular}{|c|c|c|c|c|c|c|c|c|c|c|}
\hline Ions & $\mathbf{N a}^{+}$ & $\mathbf{K}^{+}$ & $\mathbf{C a}^{2+}$ & $\mathbf{M g}^{2+}$ & $\mathbf{C l}^{-}$ & $\mathbf{S O}_{4}{ }^{2-}$ & $\mathbf{H C O}_{3}{ }^{-}$ & $\mathbf{C O}_{3}{ }^{2-}$ & $\mathbf{T o t a l}$ & $\mathbf{p H}^{2}$ at $25^{\circ} \mathbf{C}$ \\
\hline \hline $\mathrm{C}(\mathrm{mg} / \mathrm{L})$ & 3820 & 86 & 105 & 34 & 5250 & 645 & 485 & $\mathrm{NIL}$ & 10425 & 7.85 \\
\hline
\end{tabular}

\subsection{Experimental Materials}

The chemicals applied in the experiments, such as $\mathrm{NaOH}(\geq 99.5 \%), \mathrm{Na}_{2} \mathrm{CO}_{3}(\geq 99.5 \%), \mathrm{NaCl}(>99.5 \%), \mathrm{CaCl}_{2}(>96 \%)$

*Address correspondence to this author at the Enhanced Oil Recovery Research Institute, China University of Petroleum (Beijing), Beijing, 102249; Tel: 18202506889; FaX: 022-66907735;

E-mail: penglv_cup@163.com selected can meet the polymer flooding standard.

\subsection{Relationships between the Apparent Viscosity and Polymer Concentration}

The relationship between the apparent viscosity and the polymer concentration of polymer solution for the six kinds of polymers with formation brine are examined. The shear rate is $7.34 \mathrm{~s}^{-1}$ and the results are as shown in Table 3 . From Table 3, it can be seen that the viscosity of polymer solution 
Table 2. Parameters of polymers selected for the evaluation of polymer flooding.

\begin{tabular}{|c|c|c|c|c|c|c|}
\hline Polymer & MO4000 & FP3640s & FP6040s & DQ3500 & KYPAM-2 & KYPAM-5 \\
\hline \hline Manufacture & Misubishi. & SNF & SNF & DQ & Hengju Co. & Hengju Co. \\
\hline Country & Japan & France & France & China & China & China \\
\hline$M_{\mathrm{w}}\left(\times 10^{4}\right)$ & 2400 & 2000 & 2500 & 1900 & 2447 & 21.50 \\
\hline Hydrolyzing degree mol/\% & 22.46 & 31.80 & 24.60 & 37.41 & 1.050 & 25.06 \\
\hline Filtration factor & 1.04 & 1.0 & 1.2 & 0.163 & 0.071 & 0.079 \\
\hline Water insoluble matter/\% & 0.018 & 0.19 & 0.062 & $<2.0$ & $<2.0$ & 82.0 \\
\hline Dissolving time/h & $<2.0$ & $<2.0$ & $<2.0$ & 86.54 & 89.32 & 88.48 \\
\hline Solid content/\% & 91.78 & 88.17 & 89.29 & & $<2.0$ \\
\hline
\end{tabular}

Table 3. Relationship between the apparent viscosity $(\mathrm{mPa} \cdot \mathrm{s})$ and the polymer concentration $(\mathrm{mg} / \mathrm{L})\left(\mathrm{T}=72^{\circ} \mathrm{C}\right.$ shear rate $\left.: 7.34 \mathrm{~s}^{-1}\right)$.

\begin{tabular}{|c|c|c|c|c|c|c|}
\hline Concentration & $\mathbf{5 0 0}$ & $\mathbf{7 5 0}$ & $\mathbf{1 0 0 0}$ & $\mathbf{1 5 0 0}$ & $\mathbf{2 0 0 0}$ & $\mathbf{2 5 0 0}$ \\
\hline \hline Polymer & & 3.1 & 5.0 & 6.7 & 14.2 & 25.6 \\
\hline FP3640s & 1.9 & 3.0 & 4.4 & 8.2 & 14.8 & 24.2 \\
\hline FP6040s & 5.2 & 8.8 & 14.0 & 28.0 & 49.0 & 75.6 \\
\hline DQ3500 & 6.9 & 11.7 & 21.0 & 39.0 & 66.5 & 102.5 \\
\hline KYPAM-2 & 4.9 & 8.5 & 12.5 & 29.7 & 52.0 & 83.4 \\
\hline KYPAM-5 & 4.4 & 7.3 & 11.6 & 23.4 & 41.8 & 64.7 \\
\hline
\end{tabular}

is increased with the increasing of polymer concentration. The viscosity of polymer solution for polymer FP6040s, DQ3500 and KYPAM- 2 are larger than the others. Under the shear rate of $7.34 \mathrm{~s}^{-1}$, the apparent viscosity of $1500 \mathrm{mg} / \mathrm{L}$ polymer solution for polymer FP6040s, DQ3500 and KYPAM-2 are 28.0, 39.0 and $29.7 \mathrm{mPa} \cdot \mathrm{s}$ at temperature of $72^{\circ} \mathrm{C}$. From the perspective of the relationship between the apparent viscosity and the polymer concentration of polymer solution, polymer FP6040s, DQ3500, and KYPAM-2 are suitable for polymer flooding in Zahra's oil field.

\subsection{Relationship between the Apparent Viscosity and Temperature}

The relationship between the apparent viscosity and the temperature of polymer solution for the six kinds of polymers with formation brine is examined. The concentration of polymer solution is $1500 \mathrm{mg} / \mathrm{L}$ and the shear rate is $7.34 \mathrm{~s}^{-1}$. The results are as shown in Table 4 . From Table 4, it can be seen that the viscosity of polymer solution is decreased with the increasing of temperature. Under the shear rate of $7.34 \mathrm{~s}^{-1}$, the apparent viscosity of $1500 \mathrm{mg} / \mathrm{L}$ polymer solution for polymer FP6040s, DQ3500 and KYPAM-2 are $25.2,33.0,23.8 \mathrm{mPa} \cdot \mathrm{s}$ at temperature of $85^{\circ} \mathrm{C}$. The viscosity of polymer solution for polymer FP6040s, DQ 3500 and KYPAM-2 are larger than the others. From the perspective of the relationship between the apparent viscosity and the temperature, polymer FP6040s, DQ 3500, and KYPAM-2 are suitable for polymer flooding in Zahra's oil field.

\subsection{Thermo-stability Characteristics of Polymer Solution}

Fig. (1) is apparent viscosity changing of the polymers with thermal aging time, with the polymer concentration of $1500 \mathrm{mg} / \mathrm{L}$ in anaerobic condition at temperature of $72^{\circ} \mathrm{C}$. It can be seen from Fig. (1) that the apparent viscosity of polymer solution is basically remained unchanged. The polymers solution has long time thermo-stability.

\subsection{Transmission Performance of Polymer in Cores}

The static and dynamic adsorption of the polymer in core can affect the performance of the polymer flooding. Flow properties of the three kinds of polymer DQ3500, FP6040s and KYPAM-2 in the reservoir rocks are investigated through core flow test.

\section{(1). Polymer of FP6040s}

Fig. (2) is the pressure curve of four different measuring points in a core when $1500 \mathrm{mg} / \mathrm{L} \mathrm{FP6040s} \mathrm{polymer} \mathrm{solution}$ flows through the core. The core permeability is $73.0 \mathrm{mD}$. From Fig. (2), it can be seen that the pressure at different position in the core is raised slowly when polymer solution is 
Table 4. Relationship between the apparent viscosity $(\mathrm{mPa} \cdot \mathrm{s})$ and the temperature $\left({ }^{\circ} \mathrm{C}\right)\left(\mathrm{c}=1500 \mathrm{mg} / \mathrm{L}, \quad\right.$ shear rate $\left.7.34 \mathrm{~s}^{-1}\right)$.

\begin{tabular}{|c|c|c|c|c|c|c|}
\hline Temperature $\left({ }^{\circ} \mathbf{C}\right)$ & $\mathbf{4 5}$ & $\mathbf{5 5}$ & $\mathbf{6 5}$ & $\mathbf{7 0}$ & $\mathbf{7 5}$ & $\mathbf{8 5}$ \\
\hline \hline Polymer & & 18.9 & 16.3 & 14.3 & 14. & 13.5 \\
\hline FP4000 & 12.5 & 11.3 & 9.5 & 8.9 & 8.2 & 7.8 \\
\hline FP6040s & 34.5 & 32.2 & 29.9 & 28.7 & 27.4 & 25.2 \\
\hline DQ3500 & 48.6 & 44.5 & 41.0 & 39.0 & 37.8 & 33.0 \\
\hline KYPAM-2 & 36.0 & 30.8 & 29.3 & 26.3 & 24.8 & 23.8 \\
\hline KYPAM-5 & 30.7 & 27.9 & 25.2 & 23.5 & 22.7 & 19.9 \\
\hline
\end{tabular}

Table 5. Parameter of core.

\begin{tabular}{|c|c|c|c|c|c|c|}
\hline Core & Length/mm & Diameter/mm & Pore volume/ml & Porosity/ \% & Permeability of air /mD & Permeability of water/mD \\
\hline \hline $1 \#$ & 281.60 & 25.00 & 38.43 & 27.8 & 247 & 73.0 \\
\hline
\end{tabular}

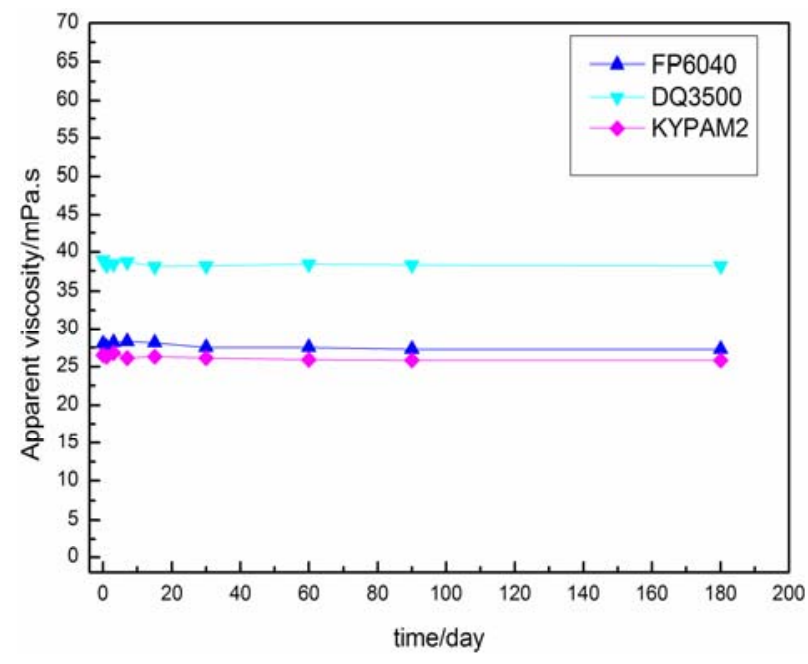

Fig. (1). Relationship between the viscosity of polymer solution and aging time. (anaerobic condition at $72{ }^{\circ} \mathrm{C}$, concentration: $1500 \mathrm{mg} / \mathrm{L}$, shear rate $: 7.34 \mathrm{~s}^{-1}$ )

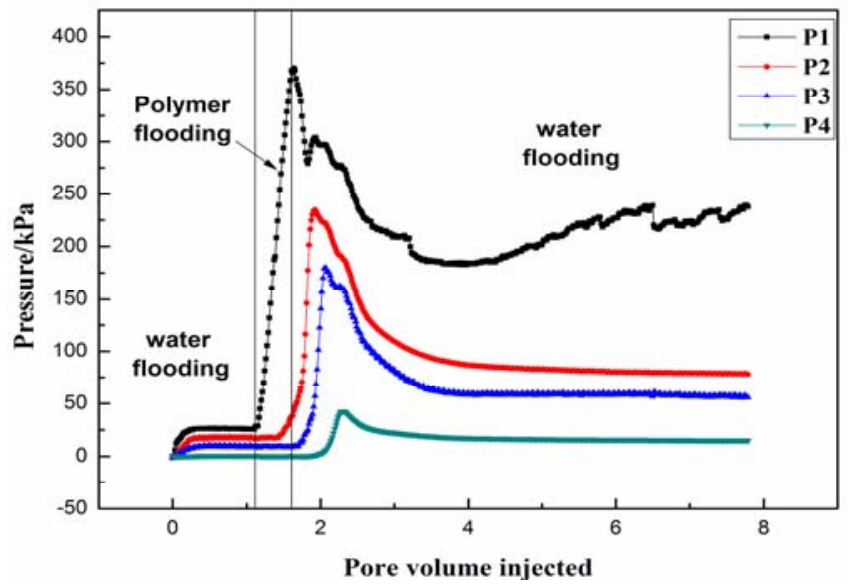

Fig. (2). $1500 \mathrm{mg} / \mathrm{L} \mathrm{FP6040s} \mathrm{solution} \mathrm{injection} \mathrm{performance} \mathrm{in} \mathrm{a}$ core. injected into the core. And then water replaced the polymer solution when the polymer solution injection volume reached $0.5 \mathrm{PV}$ (pore volume). The pressure at different position in the core rose slowly, but along with the water injection, the pressure at different position in the core is declined slowly and then to be stability. The dramatic change of pressure is not appeared.

\section{(2). Polymer of KYPAM-2}

Fig. (3) is the pressure curve of four different measuring points in a core when $1500 \mathrm{mg} / \mathrm{L}$ KYPAM-2 polymer solution flows through the core. The core permeability is $82.6 \mathrm{mD}$. It can be seen from Fig. (3) that the pressure at different position in the core is raised slowly when polymer solution is injected into the core. And then water replaces the polymer solution when the polymer solution injection volume reaches $0.5 \mathrm{PV}$ (pore volume). The pressure at different position in the core rose slowly along with the water injection, the pressure at different position in the core is declined slowly and then to be in stability state. The dramatic change of pressure is also not appeared.

\section{(3). Polymer DQ3500}

Fig. (4) is the pressure curve of four different measuring points in a core when $1500 \mathrm{mg} / \mathrm{L}$ DQ3500 polymer solution flows through the core. The core permeability is $59.3 \mathrm{mD}$. It can be seen from Fig. (4) that the pressure at different position in the core is raised slowly when polymer solution is injected into the core. And then water replaces the polymer solution when the polymer solution injection volume reaches $0.5 \mathrm{PV}$ (pore volume). The pressure at different position in the core is also risen slowly. But along with the water injection, the pressure at different position in the core is declined slowly and then to be in stability stat. The pressure does not present dramatic changes. 
9 Table 6. Parameter of core.

\begin{tabular}{|c|c|c|c|c|c|c|}
\hline Core & Lenth/mm & Diameter/mm & Pore volume/ml & Porosity/\% & Permeability of air/mD & Permeability of water/mD \\
\hline \hline $2 \#$ & 284.12 & 25.00 & 31.07 & 22.3 & 167 & 82.6 \\
\hline
\end{tabular}

Table 7. Parameter of core.

\begin{tabular}{|c|c|c|c|c|c|c|}
\hline Core & Lenth/mm & Diameter/mm & Pore volume/ & Porosity $\%$ & Permeability of air/mD & Permeability of water/mD \\
\hline \hline $3 \#$ & 283.78 & 25.00 & 30.00 & 21.5 & 158 & 59.3 \\
\hline
\end{tabular}

Table 8. Adsorption of $\mathbf{t}$ polymers with different concentration on natural rock particles $(\mu \mathrm{g} / \mathrm{g})$.

\begin{tabular}{|c|c|c|c|c|}
\hline Polymers & Concentration $(\mathbf{m g} / \mathbf{L})$ & $\mathbf{4 0 0}$ & $\mathbf{8 0 0}$ & $\mathbf{1 0 0 0}$ \\
\hline \hline FP6040 & 1276 & 1396 & 1464 & 1492 \\
\hline DQ3500 & 1012 & 1060 & 992 & 876 \\
\hline KYPAM-2 & 1280 & 1104 & 1496 & 1172 \\
\hline
\end{tabular}

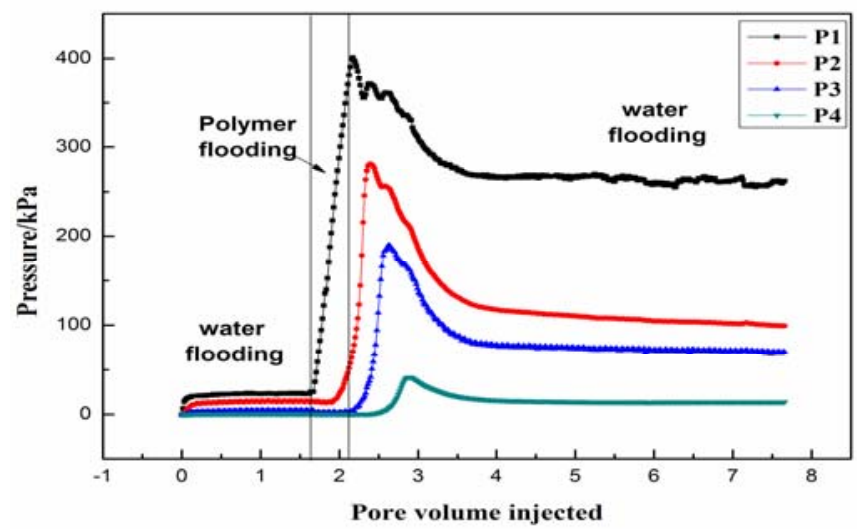

Fig. (3). $1500 \mathrm{mg} / \mathrm{L} \mathrm{KYPAM-2solution} \mathrm{injection} \mathrm{performance} \mathrm{in} \mathrm{a}$ core.

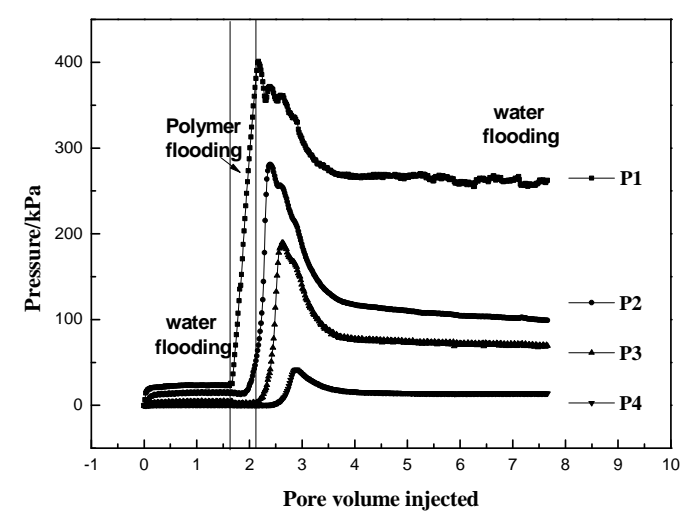

Fig. (4). $1500 \mathrm{mg} / \mathrm{L} \mathrm{DQ} 3500$ solution injection performance in a core.

\subsection{Static Adsorption of the Polymer on Natural Rock Particles}

Static adsorption of the polymer FP6040s, DQ3500 and KYPAM-2 on the surface of the natural rock particles (100 mesh) is examined [5] at $72{ }^{\circ} \mathrm{C}$. The experimental results are shown in Table 8. It can be seen from Table 8 that static adsorption of the polymer FP6040s, DQ3500 and KYPAM 2 do not change a lot with the increasing of concentration of polymer solution. Static adsorption amount of polymer FP6040s, DQ3500, KYPAM - 2 is approximately 1000 $\mathrm{mg} / \mathrm{g}$, especially the static adsorption amount of DQ3500 is the smallest.

\subsection{Dynamic Adsorption of Polymer on Surface of Natural Core}

Dynamic adsorption of polymer FP6040s, DQ3500, KYPAM-2 with a concentration of $1500 \mathrm{mg} / \mathrm{L}$ on the surface of the natural rock is measured by core flow test at $72{ }^{\circ} \mathrm{C}$. Parameters of cores are shown as in Table 9. The results are shown in Table 10. It can be seen from Table $\mathbf{1 0}$ that dynamic adsorption of polymer FP6040s, DQ3500, KYPAM-2 on the surface of the core are 196, 125 and 159 $\mathrm{mg} / \mathrm{L}$, respectively. The dynamic adsorption of the polymer DQ3500 is the smallest.

It can be seen from the static and dynamic adsorption results that DQ3500 adsorption is significantly smaller than the other two polymers. In practical application of polymer solution flooding the reducing of the polymer adsorption can reduce the amount of injection volume which is helpful to displacement efficient. So DQ3500 is chosen as the most suitable polymer for polymer solution flooding in Zahra oilfield.

\subsection{Flooding Effect on Natural Core}

Polymer solution flooding effect is evaluated by displacement experiment in natural core. Fig. (6) is the 
Table 9. Parameter of cores.

\begin{tabular}{|c|c|c|c|c|c|c|}
\hline Core & Length of core/mm & Diameterof core/mm & Pore Volume/ml & Porosity/\% & $\mathrm{Kg} / \mathrm{mD}$ & $\mathrm{K}_{\mathrm{w}} / \mathbf{m D}$ \\
\hline $4 \#$ & 287.60 & 25.00 & 34.16 & 24.2 & 173 & 66.3 \\
\hline $5 \#$ & 286.00 & 25.00 & 33.35 & 23.8 & 184 & 50.4 \\
\hline $6 \#$ & 286.34 & 25.00 & 32.78 & 23.3 & 182 & 49.1 \\
\hline
\end{tabular}

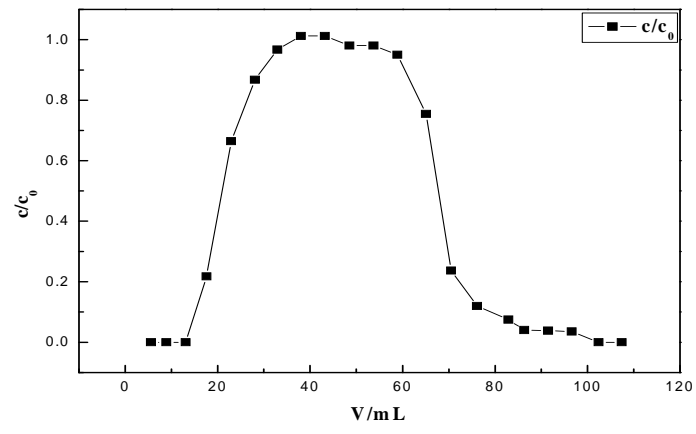

(a). Polymer DQ3500

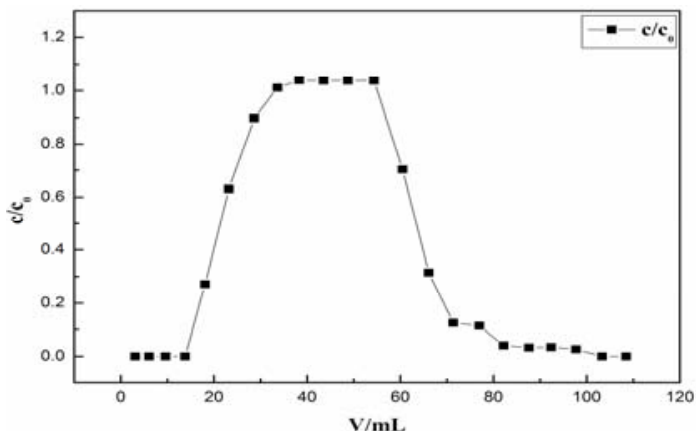

(b). Polymer KYPAM-2

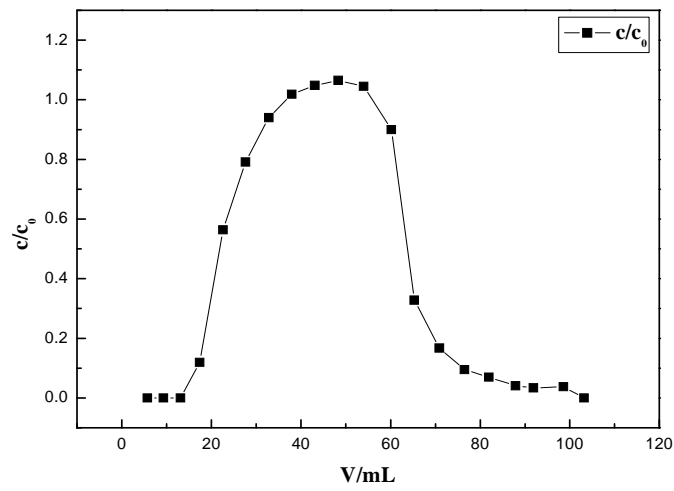

(c).Polymer FP6040s

Fig. (5). Dynamic adsorption of polymer on cores.

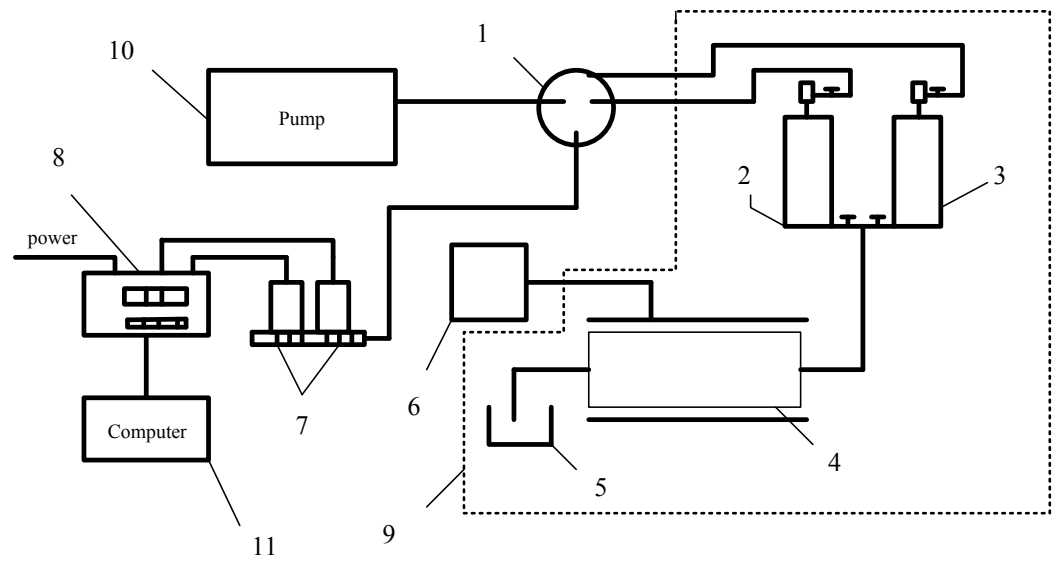

1. Valve 2. Tank of water 3. Tank of polymer solution 4. Core holder 5. Beaker 6. Pump 7. Pressure tranformer 8. Pressure meter 9. Heating box 10. Pump 11 Computer

Fig. (6). Schematic diagram of polymer flooding for Zahra crude oil apparatus used in experiment

schematic diagram of polymer flooding for Zahra crude oil apparatus used in displacement experiment.
Displacement experiment results of polymer solution of DQ3500 with $1500 \mathrm{mg} / \mathrm{L}$ in $25 \mathrm{~cm}$ long and permeability of 
9 Table 10. Dynamic adsorption of polymers in

\begin{tabular}{|c|c|c|c|}
\hline core. $\quad$ Polymer & FP6040 & DQ3500 & KYPAM-2 \\
\hline \hline Adsorption amount $(\mu \mathrm{g} / \mathrm{g})$ & 196 & 125 & 159 \\
\hline
\end{tabular}

Concentration of polymer solution: $1500 \mathrm{mg} / \mathrm{L}$

Table 11. Parameter of cores.

\begin{tabular}{|c|c|c|c|c|c|c|}
\hline Core & Length of core / $\mathbf{m m}$ & Diameter of core/mm & Pore Volume / $\mathbf{m l}$ & Porosity / \% & $\mathbf{K g} / \mathbf{m D}$ & $\mathbf{K} \mathbf{W} / \mathbf{m D}$ \\
\hline \hline $7 \#$ & 277.58 & 25.00 & 24.11 & 17.8 & 114.8 \\
\hline $8 \#$ & 260.22 & 25.00 & 26.43 & 20.4 & 1800 \\
\hline
\end{tabular}

Table 12. Displacement performance of $1500 \mathrm{mg} / \mathrm{L}$ polymer solution of DQ 3500 .

\begin{tabular}{|c|c|c|c|c|c|c|}
\hline Core & Oil Saturation/\% & $\begin{array}{c}\text { Oil Recovery by } \\
\text { Water/\% }\end{array}$ & $\begin{array}{c}\text { Ultimate } \\
\text { Recovery/\% }\end{array}$ & $\begin{array}{c}\text { Enhanced Oil } \\
\text { Recovery/\% }\end{array}$ & $\begin{array}{c}\text { Resistance } \\
\text { Factor/\% }\end{array}$ & $\begin{array}{c}\text { Residual Resistance } \\
\text { Factor/\% }\end{array}$ \\
\hline \hline $7 \#$ & 56.4 & 43.44 & 50.53 & 7.09 & 4.47 & 1.35 \\
\hline $8 \#$ & 58.8 & 29.77 & 36.87 & 7.1 & 5.32 & 2.36 \\
\hline
\end{tabular}

20-240 mD natural cores at $72{ }^{\circ} \mathrm{C}$ are shown from Fig. (7) to Fig. (10) and Table 12, respectively. The oil used in displacement experiment is the dewatered Zahra crude oil. The displacement procedure was as follows $[6,7]$ :

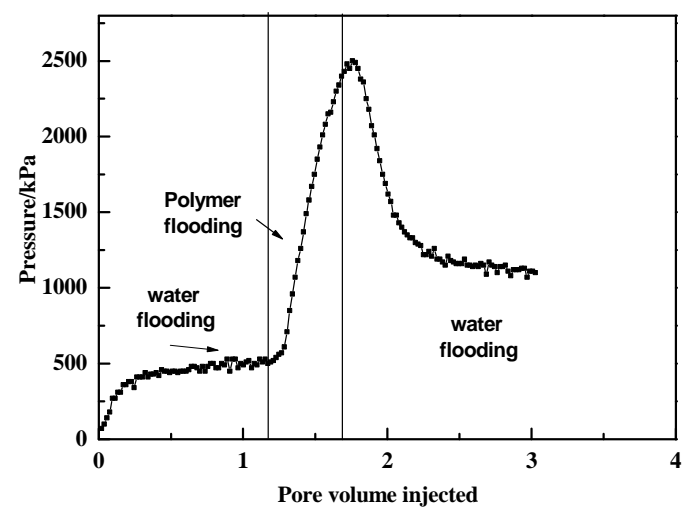

Fig. (7). Pressure in displacement experiment in core 7\#.

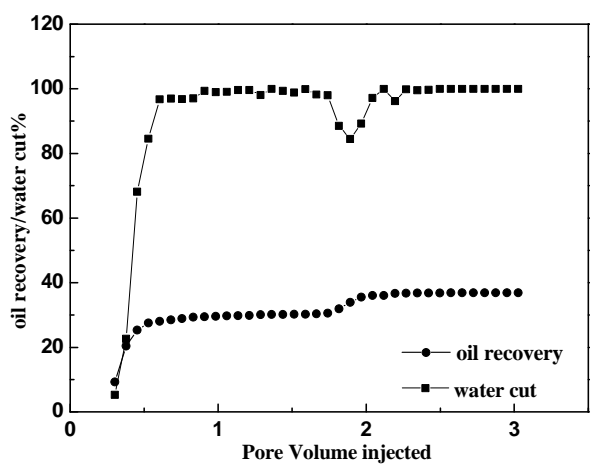

Fig. (8). Water cut /oil recovery in displacement experiment in core $7 \#$.
1. The core is saturated with water in a vacuum state. So the pore volume is calculated by the water volume.

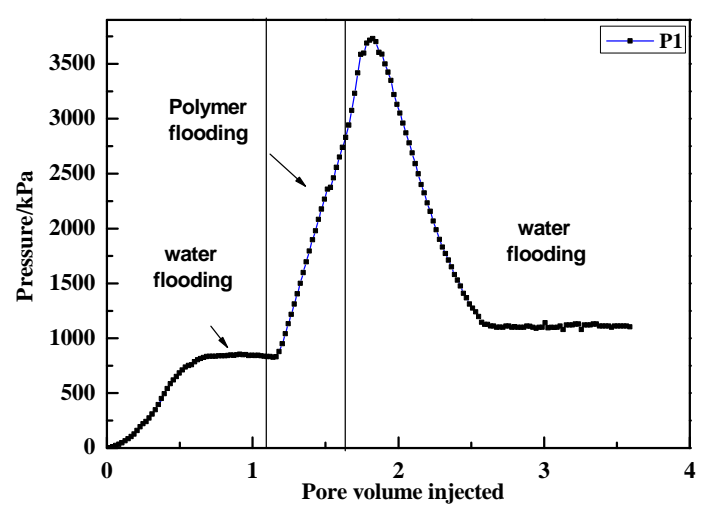

Fig. (9). Pressure in displacement experiment in core $8 \#$.

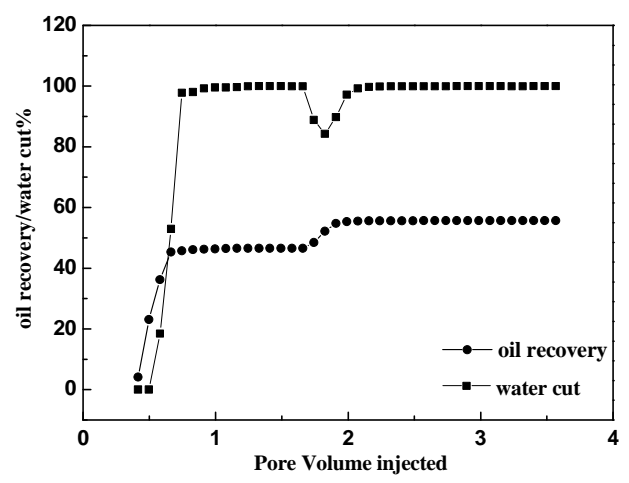

Fig. (10). Water cut /oil recovery in displacement experiment in core $8 \#$. 
2. The core is flooded with the dewatered Zahra crude oil until no more water could be displaced. The oil saturation is calculated by the ratio of saturation oil volume to the saturation water volume in step 1 .

3. The core is water flooded at a rate of $0.1 \mathrm{ml} / \mathrm{min}$. When water cut reaches $98 \%$, the core is flooded by of polymer solution of DQ3500. When the injected polymer solution volume reaches $0.5 \mathrm{PV}$, the core is flooded by water again until no more oil could be displaced.

The cores used in the displacement experiment are shown in Table 11 and the results of the displacement experiment are shown in Table 12.

It can be seen from Table 12 that enhanced oil recovery by polymer solution of DQ3500 in natural core is about $7 \%$ and the water cut is significantly decreased about $20 \%$.

\section{CONCLUSION}

1. From the view of viscosity-concentration/temperature performance and the static/dynamic adsorption of the polymer in core, DQ3500 is chosen as the most suitable polymer for Zahra oilfield flooding.
2. Enhanced oil recovery by polymer solution of Qaqing 3500 in natural core is about $7 \%$ and the water cut is significantly decreased about $20 \%$.

\section{REFERENCES}

[1] N. Mungan, F.W. Smith, J.L. Thompson, "Some aspects of polymer floods", J. Pet. Technol., vol. 237, pp. 1143-1150, September 1966.

[2] Y. Cohen, F.R. Christ, "Polymer retention and adsorption in the flow of polymer solutions through porous media," SPE. Res. Eng., vol. 1, pp.113-118, February 1986.

[3] R. Ibragimov, I. Gusenov, G. Tatykhanova, Z. Adilov, N. Nuraje, S. Kudiabergenov, "Study of gellan for polymer flooding", $J$. Dispers. Sci. Technol., vol. 34, pp.1240-1247, September 2013.

[4] S. Q. Liu, J. C. Zhang, J. C. Xu, "Investigation on polymer adsorption and retention in a polymer flooded reservoir", $A d v$. Mater. Res., vol. 734, pp.1200-1203, August 2013.

[5] S. Shaofu, Z. Bo, Z. Suiwang, S. Lei, "Research Progress of Determining Methods for HPAM", Guangdong Chem. Ind., vol.39, pp.6-8, April 2012

[6] S. B. Shaker, A. Skauge, "Enhanced oil recovery (EOR) by combined low salinity water/polymer flooding", Energy Fuels, vol.27, pp. 1223-1235, February 2013.

[7] J. Taber, "Dynamic and static forces required to remove a discontinuous oil phase from porous media containing both oil and water", Soc. Pet. Eng. J., vol. 9, pp. 3-12, January 1969.

Received: September 5, 2014

Revised: December 22, 2014

Accepted: January 8, 2015

(C) Lv et al.; Licensee Bentham Open.

This is an open access article licensed under the terms of the Creative Commons Attribution Non-Commercial License (http://creativecommons.org/licenses/by-nc/3.0/) which permits unrestricted, non-commercial use, distribution and reproduction in any medium, provided the work is properly cited. 